\title{
Exportación de la contaminación en Chile: Análisis de procedimientos sancionatorios de la Superintendencia del Medio Ambiente, 2013-2019
}

Kay Bergamini. Pontificia Universidad Católica de Chile, Santiago, Chile.

Rosa-María Dextre. Universität Heidelberg, Santiago, Chile.

RESUMEN | El modelo económico basado en la extracción y exportación de recursos naturales a países procesadores de materias primas, y la influencia de las grandes potencias o países desarrollados en esa condición, han provocado deterioro ambiental. En esta investigación se analiza los datos de los procedimientos sancionatorios impuestos por la Superintendencia del Medio Ambiente de Chile entre los años 2013 y 2019 a los titulares de los proyectos de inversión que incumplieron con la normativa ambiental vigente. Se comprueba que los rubros con mayor formulación de cargos corresponden a actividades de exportación (minería, agropecuario, instalaciones fabriles, y pesca y acuicultura), cuyas multas por incumplimientos ambientales ascienden a casi 411.000.000 usD y son liderados, después de Chile, por capitales de inversión extranjera. Se argumenta que estas compañías de países con mejores estándares ambientales no aplican las mismas condiciones de operación en Chile. Esto permite mostrar carencias en la implementación de políticas estatales y empresariales relacionadas con el discurso del desarrollo sostenible del país.

PALABRAS CLAVE | geografía económica, gestión ambiental, medioambiente.

ABSTRACT | The economic model based on the extraction and export of natural resources to countries that process raw materials, and the influence of the great powers or developed countries in this condition, has caused environmental deterioration. This research analyzes the data of the sanctioning procedures imposed by the Superintendence of the Environment of Chile between 2013 and 2019 to the holders of investment projects that failed to comply with current environmental regulations. It is found that the items with the highest number of charges filed correspond to export activities (mining, agriculture and livestock, manufacturing facilities, and fishing and aquaculture) whose fines for environmental non-compliance amount to almost 411,000,000 USD and are led, after Chile, by foreign investment capitals. It is argued that these companies from countries with better environmental standards do not apply the same operating conditions in Chile. This shows shortcomings in the implementation of state and business policies related to the country's sustainable development discourse.

KEYWORDS | economic geography, environmental management, environment. 


\section{Introducción}

Desde la instalación del pensamiento neoliberal en Chile a partir de 1973 (ÁvilaFuenmayor, 2005; Jenkins, 2003), entendido como la forma de establecer políticas económicas que conceden al mercado un papel central por encima de la organización social de un país (Ffrench-Davis, 2003), el nuestro ha tenido periodos de crecimiento constante de su Producto Bruto Interno (PBI), según informa el Banco Mundial (2019). Entre 1990 y 2000, se alcanzó una cifra promedio del 6\%, muy por encima de la media mundial del 3,2\%. Asimismo, en el primer decenio de este siglo, entre 2004 y 2006, se logró un crecimiento máximo del 6,4\%, que ha tenido éxito sobre todo en materias de mejoras de ingreso y reducción de la pobreza. Por su parte, la Organización para la Cooperación y el Desarrollo Económico (ocDE) sostiene que los chilenos de hoy están mejor que en el pasado, gracias a una economía estable y abierta: "El ingreso per cápita era solo el 26\% del de los Estados Unidos en la década de 1990, mientras que hoy en día el ingreso promedio de un chileno es igual al 40\% de ingresos de un ciudadano estadounidense" (Organisation for Economic Co-operation and Development / United Nations [oECD/UN], 2018). Esto se puede evidenciar en las cifras actualizadas del Banco Mundial (2019), donde la tasa de incidencia de personas que viven bajo la línea de la pobreza nacional disminuyó del 36\% al 8,6\% entre los ańos 2000 y 2017, cifras respectivas.

En el caso chileno, este crecimiento económico se ha dado en un contexto de aumento de las exportaciones, sobre todo de recursos naturales; en promedio, desde 1990, el 63,6\% del рві de Chile corresponde al comercio, es decir, al sector de exportaciones e importaciones de bienes y servicios (Banco Mundial, 2019). El mayor aporte de este sector a la economía nacional se dio en 2008, donde alcanzó el 80,8\%. Específicamente, la expansión de las exportaciones de bienes y servicios ha sido, según Giljum (2004), "el núcleo de la reestructuración neoliberal de la economía chilena desde sus inicios” (p. 243).

Para las economías locales de Latinoamérica, la ocDE reconoce los beneficios de contar con mercados abiertos al comercio internacional y la inversión extranjera (Romo Murillo, 2007). Sin embargo, las dinámicas de las reformas económicas implementadas merecen especial atención, ya que, con frecuencia, "el debate comercio medio ambiente se enmarca entre los intereses y preocupaciones ambientales existentes en los países ricos y, por el otro lado, los países en desarrollo que buscan alcanzar mayores tasas de crecimiento aun a costa del deterioro ambiental" (Romo Murillo, 2007, p. 11).

Precisamente para Chile, su principal desafío es superar la dependencia que tiene su modelo económico respecto de la extracción de sus recursos naturales (OECD/UN, 2018). Desde tal perspectiva, en este artículo se analiza la relación entre la exportación de productos (principalmente recursos naturales) por sector económico, el país de origen de los capitales de inversión asociados a estos sectores, y el incumplimiento de la normativa ambiental de Chile. El objetivo es evidenciar lo que se denominará como "exportación de la contaminación", entendida como el desbalance ambiental negativo ocurrido en el país, producto de su modelo económico basado en la extracción y exportación de recursos naturales a países procesadores de materias primas, 
y la influencia de las grandes potencias o países desarrollados en esa condición. $\mathrm{Al}$ respecto, en este trabajo se establecen dos hipótesis: i) los sectores económicos involucrados en la actividad extractiva exportadora cometen más infracciones a las licencias ambientales que otros sectores económicos, tanto en número como en montos por multas; ii) los capitales de origen extranjero que representan a las empresas que operan en Chile cometen más infracciones a las licencias ambientales que aquellos de origen nacional, tanto en número como en montos por multas.

En la primera parte del artículo se presentan las consideraciones teóricas y empíricas para entender por qué la globalización comercial está generando malestar en aquellos países cuyo modelo de desarrollo es altamente dependiente de la exportación de materia prima. Asimismo, se pone en discusión la relación entre el crecimiento económico basado en la exportación de recursos naturales y las externalidades ambientales, así como los supuestos teóricos que lo estudian. Una vez presentado el marco teórico, se pone en contexto la situación actual de la institucionalidad ambiental en Chile y la evolución paralela del sector exportador del país. En la tercera sección se resume el diseño metodológico utilizado para estudiar las variables mencionadas. Después se presentan los resultados de la investigación, para terminar el artículo con las discusiones y conclusiones finales del estudio.

\section{Consideraciones teóricas y empíricas}

\section{Globalización y comercio}

La liberalización económica basada en el libre comercio, la reducción del gasto fiscal y la privatización, se pensaron como componentes de una buena estrategia de desarrollo para América Latina durante los años ochenta y noventa (Stiglitz, 2002). Sin embargo, la exclusión de políticas sociales y ambientales, transversales y específicas para cada caso, ha hecho que los resultados sean diferentes a los esperados (Stiglitz, 2018). Especialmente, la evolución de la transversalidad de las temáticas ambientales en Chile ha tenido que correr a pasos agigantados para alcanzar los niveles y estándares de la economía del libre mercado (Barton et al., 2007).

En el comercio internacional, el modelo neoliberal adoptado en Chile generó las condiciones adecuadas para implementar un proceso de liberalización del intercambio de bienes y servicios a través de la eliminación sostenida de cualquier forma de barrera comercial (Ffrench-Davis, 2003). De esta forma, hasta 2018, Chile era reconocido por el Banco Mundial como el caso de liberación económica más exitoso de América Latina (Comision Económica para América Latina y el Caribe [CEPAL], 2018). Asimismo, es la 42a economía de exportación más grande del mundo y la 61 a economía más compleja según el Índice de Complejidad Económica (The Obsevatory of Economic Complexity [oec], 2018). En ese sentido, la economía del país ha sido altamente dependiente del comercio internacional $(57,5 \%$ del PBI del país), especialmente de la exportación de bienes y servicios (28,8\% del PBI) (Banco Mundial, 2019); solo en el año 2018 se exportaron 76,8 millones de dólares ғOв en bienes y servicios, de los cuales el $24,3 \%$ corresponde a minerales de cobre y oro (oec, 2018). Sin embargo, desde el último decenio del siglo xx se viene discutiendo si la liberalización de la economía en América Latina, sustentada en la exportación 
de materias primas, ha provocado como efecto un mayor deterioro ambiental de los países y, sobre todo, de los territorios que se han incorporado a las dinámicas de la globalización (Beck, 2008; Gudynas, 2019; Temkin Yedwab et al., 2018).

La mayor retórica de la globalización se da a través de la globalización comercial, fenómeno al que Stiglitz (2018) sentencia como un ejemplo de mala gestión de la globalización, debido a los descontentos sociales que proliferan en esta era. Según el economista, los términos de las negociaciones, la reducción de aranceles y otras barreras al comercio han generado beneficios para los países desarrollados por sobre los percibidos por los que se encuentran en desarrollo, y también para las grandes empresas, en contra de sus trabajadores y el medioambiente (Stiglitz, 2018). Así, Pérez-Rincón (2007) sostiene que, "los niveles de consumo externo, a través del comercio internacional, trasladan buena parte de los costos sociales y ambientales a territorios y zonas específicas dentro de un país" (p. 354).

La adopción de estas economías-mundo en América Latina, asumidos como los únicos modelos para lograr el desarrollo, se han venido consolidando con fuerza conforme se generaliza el capitalismo en la región (Ianni, 1996). No obstante, es importante resaltar que la adopción de un mismo estilo o modelo de desarrollo en la región ha tenido niveles de profundización variados en la estructura económica local, especialmente en el grado de intervención del sector público en la economía de cada país (Gligo V., 2006). De esta forma, los patrones dominantes que han impulsado las economías de Latinoamérica, especialmente la de Chile, han sido el incremento de las exportaciones y la presencia, cada vez mayor, de capitales de inversión extranjera directa en sus territorios (Ffrench-Davis \& Díaz, 2019).

\section{Crecimiento económico y contaminación ambiental}

En América Latina, la construcción de idearios de crecimiento surgieron a mediados del siglo xx con la traducción al español de las obras de Joseph A. Schumpeter o de W. Arthur Lewis referidas al desarrollo y crecimiento económico (Gudynas, 2019). Si bien desarrollo y crecimiento suelen utilizarse de forma alternada, no significan lo mismo (Márquez-Ortiz et al., 2020). Se debe entender por desarrollo económico "la transformación de las estructuras económicas para satisfacer las necesidades de la población, asegurándole un mayor bienestar general” (Márquez-Ortiz et al., 2020, p. 250); y por crecimiento económico, "el aumento cuantitativo y cualitativo de las rentas reales de un país en un lapso de tiempo determinado" (Fermoso, 1997, p. 123). Este último es eje central para este trabajo de investigación.

A finales de 1960 surgió el reconocimiento de los límites ecológicos del crecimiento económico con el informe "Los límites del crecimiento", encargado por el Club de Roma y presentado en 1972 en la Conferencia de Estocolmo (Gudynas, 2019). En este informe se alerta sobre los riesgos del consumismo, la industrialización, la sobreexplotación de los recursos naturales, la contaminación, entre otros, para la sostenibilidad del planeta (Meadwos et al., 1972). A partir de ahí, los postulados de la economía clásica encuentran una barrera tangible en los sistemas ecológicos como sistemas mayores que contienen a los sistemas económicos, y no al revés (Gudynas, 2010). 
En la actualidad, de acuerdo con el último informe del Panel Intergubernamental de Cambio Climático (IPCC, por sus siglas en inglés), se sabe que la temperatura del aire en la superficie terrestre ha aumentado casi el doble de la temperatura media global desde el periodo preindustrial (Pörtner et al., 2019). Asimismo, la Evaluación de los Ecosistemas del Milenio (MEA, por sus siglas en inglés), documento publicado en 2005, vuelve a encender la alarma sobre el futuro de la humanidad. Las transformaciones hechas por el hombre al entorno natural para su aprovechamiento han resultado costosas para los ecosistemas (Reid et al., 2005). Su degradación, en gran medida irreversible, no solo afecta a los sistemas naturales y su capacidad de autorregulación, sino, además, a los sistemas sociales: la MEA estima que una mayor degradación de los ecosistemas también supone un incremento de la pobreza y mayores desigualdades y disparidades para los grupos de personas más vulnerables (Reid et al., 2005).

A pesar de la evidencia científica que alerta sobre la crisis ecológica mundial, según Gudynas (2019), en América Latina, "las cuestiones ambientales no han alcanzado a convertirse en un tema clave” (p. 261). En ese sentido, el marco teórico de esta investigación gira en torno a la siguiente pregunta: ¿Crecimiento económico o contaminación ambiental? Para responder esta interrogante es preciso analizar supuestos teóricos que permitan predecir los diversos factores que intervienen en la existencia -o no- de una relación directa entre crecimiento económico y contaminación o degradación ambiental. Temkin Yedwab et al. (2018) sostienen que, desde la teoría económica neoclásica, hay tres perspectivas ideales para predecir esta relación: la competencia hasta el final, los paraísos de la contaminación, y la curva ambiental de Kuznets (CAK).

Las dos primeras hipótesis se relacionan estrechamente con la búsqueda de la ventaja competitiva del libre mercado, traducido en menores costos de producción, donde las empresas tienden a invertir en regiones con regulaciones ambientales laxas que, a su vez, funcionan como paraísos o polos de atracción para la inversión sucia o contaminante (Temkin Yedwab et al., 2018). En el contexto latinoamericano, según Queiroz-Sperotto (2018), la hipótesis de los paraísos de la contaminación toma especial interés debido a la creciente preocupación de la migración de industrias contaminantes a países con reglamentos ambientales menos exigentes. Si bien existen diversos aspectos que han dificultado su corroboración total, en la industria de la celulosa es posible evidenciar un claro desplazamiento de los centros productivos desde los países desarrollados a los que se encuentran en desarrollo (QueirozSperotto, 2018). En el caso chileno, Zebryte y Villegas-Benavente (2016) sostienen que presenta características de un país-refugio de contaminación, debido a que los instrumentos legales ambientales favorecen y protegen la inversión extranjera directa en el manejo y uso de recursos naturales.

Por su parte, la curva ambiental de Kuznets es una curva U invertida que muestra la variación en el tiempo del crecimiento económico y la degradación ambiental (Catalán, 2015; Sánchez \& Caballero, 2019; Vega-Quezada et al., 2019). El principal fundamento de esta hipótesis sostiene que, conforme aumentan los ingresos de un país habrá una menor presión sobre el ambiente, motivo por el cual los países desarrollados destinan más recursos económicos a la protección ambiental (Temkin 
Yedwab et al., 2018). Según Zilio (2015), la teoría de la CAK tiene tres fundamentos principales que pueden explicar su aplicación a países en desarrollo: i) la elasticidad de ingreso de la demanda de calidad ambiental; ii) el efecto escala, composición y tecnología; y iii) los efectos del comercio.

El primer fundamento asume que solo las sociedades más desarrolladas que han logrado satisfacer sus necesidades básicas empezarán a demandar mejoras en la calidad ambiental y, por lo tanto, la presión para invertir la relación directa entre degradación ambiental y crecimiento económico será mayor (Zilio, 2010, 2015).

$\mathrm{El}$ segundo fundamento hace referencia a las tres fases que atraviesa la configuración de la CAK: el efecto escala aparece en la fase inicial y se interpreta como el deterioro necesario del ambiente para sostener el crecimiento de la economía; a medida que la economía ya industrializada alcanza el punto máximo de desarrollo, hay una mayor preocupación por el ambiente y, por lo tanto, se inicia la transición hacia una economía menos contaminante; a esto se le denomina el efecto composición. El efecto tecnología explica el comportamiento negativo de la curva, ya que una economía estable puede permitirse invertir en ciencia y tecnologías limpias (Zilio, 2015). Los efectos del comercio interpretan la CAK tomando los efectos de escala, composición y tecnología, combinados con la posibilidad de "exportar e importar" el daño ambiental, gracias al crecimiento del comercio internacional (Stern, 2004). En este supuesto, el efecto escala puede redireccionarse o relocalizarse en otros países, según la dirección de los flujos comerciales más contaminantes (Zilio, 2015).

Para el contexto latinoamericano, Zilio (2015) resalta que los dos primeros fundamentos de la CAK son discutibles. Señala al respecto que la elasticidad de ingreso de la demanda de calidad ambiental no puede probarse de forma determinante en países muy pobres, ya que un mayor nivel de ingresos no siempre implica una mayor disposición a pagar por los bienes y servicios ambientales, especialmente si persisten prácticas de sobreexplotación socialmente aceptadas (Zilio, 2015). El efecto escala, composición y tecnología pierde solidez en países de la región, ya que para invertir la CAK, los efectos composición y tecnología solo aparecerán si se logra superar el efecto escala, que difícilmente se transforma, porque los recursos económicos se destinan a programas de servicios básicos y asistencia social, y no en la industrialización (Zilio, 2015). Para Chile, la evaluación del efecto escala muestra una tendencia al alza del volumen de exportación de industrias ambientalmente sensibles entre 1980 y 1995; en el efecto composición se observa una disminución de la contribución de la industria minera al valor total exportado en el mismo periodo de análisis y un aumento de los índices de especialización de otros sectores industriales; en el efecto tecnología, si bien se observa un aumento de las importaciones de bienes capitales, los índices de especialización tecnológica se mantienen invariables (Schaper, 1999).

Latinoamérica en general es un escenario atractivo para probar la existencia de la CAK. No obstante, según Falconí, Burbano y Cango (2016), hace falta considerar otros factores, como el tipo de contaminante en estudio, el país y el periodo de análisis para aplicar la CAK. En cambio, para Jenkins (2003), un tipo de estudio más recomendable para examinar los efectos del crecimiento económico a través de la liberalización comercial, es analizar la variación en el tiempo del "nivel de 
contaminación versus el comercio”, específicamente para la exportación. Sostiene este autor que, si las exportaciones de un país producen más contaminación que sus importaciones, se trata de un exportador neto de recursos ambientales y, por lo tanto, especializado en industrias relativamente contaminantes.

La especialización de la contaminación se basa en las economías de aglomeración, donde la actividad productiva se instala en sectores geográficos similares (regiones, ciudades o barrios, según la escala de análisis), para aprovechar las externalidades positivas que genera la localización cercana; sin embargo, como resultado puede provocar un mayor deterioro ambiental (Torres Preciado \& Polanco Gaytán, 2016). Si bien este deterioro puede ser similar al de los paraísos de contaminación, el enfoque no se plantea desde la perspectiva normativa, sino del aprovechamiento de las ventajas competitivas que produce a ciertos sectores económicos la localización cercana (CEPAL, 2005). En la misma línea, con énfasis en la especialización de la competitividad, la teoría de Prebisch plantea que el comercio monetario de bienes y capital entre países del norte (desarrollados) y del sur (en vías de desarrollo) genera costos ambientales desfavorables para los países exportadores del sur y, por lo tanto, la situación estructural de los sectores favorecería esta situación (Pérez-Rincón, 2006).

Finalmente, respecto de la "exportación de la contaminación", se detectan en la literatura cuatro aproximaciones conceptuales. En primer lugar, la mayor parte de los autores hace referencia al concepto como "contaminación transfronteriza", es decir, polución que viaja principalmente por aire o agua hacia otros países (Davis, 1984; Mari et al., 2004; Pochanart et al., 2004). En segundo lugar, otros autores hacen referencia a dicho fenómeno como el empuje de empresas hacia países con normativas ambientales más laxas (Hall, 2009; Furuoka \& Lo, 2005), de forma similar a lo que ocurre en los paraísos de la contaminación previamente citados. En tercer lugar, el concepto se asocia al traslado de residuos contaminantes de un país a otro para su almacenamiento (Meekosha, 2011).

Para cerrar, la cuarta línea conceptual, que es la desarrollada en este trabajo, se relaciona con la planteada por Yu, Feng y Hubacek (2014) -a partir de un trabajo de Giljum (2004) basado en la situación de Chile-, en la cual se indica que "las economías centrales están agotando la capacidad ecológica de las regiones extractivas al importar productos intensivos en recursos y han trasladado la presión ambiental a las regiones más pobres a través de la exportación de contaminación" (p. 157). En dicho contexto, es posible argumentar que un desbalance ambiental negativo en Chile como producto de su modelo económico basado en la extracción y exportación de recursos naturales a países procesadores de materias primas, y la influencia que tienen los países desarrollados en tal situación, es lo que se entiende por "exportación de la contaminación".

\section{Situación actual de la institucionalidad ambiental y las exportaciones chilenas}

Desde el periodo de inicio de la liberalización de la economía en Chile, entre los años 1974 y 1981 (Agosin, 1999), es posible clasificar la evolución de la institucionalidad ambiental del país en tres grandes etapas. En el primer periodo, entre 1980 y 1994 , se hace un reconocimiento constitucional del derecho ambiental, y se 
trabaja en la elaboración de una ley que permita su aplicación. Para autores como Carruthers (2001), partiendo desde la época de dictadura y luego en democracia, la evolución de la normativa ambiental ha sido acorde al modelo económico y ha resultado enemiga de la sustentabilidad, con recompensas para aquellos que externalizan de manera más efectiva los costos ambientales y sociales de producción, careciendo el Estado de autonomía y capacidad para corregir las fallas de mercado.

Un segundo periodo, a partir de 1994, abarca el que se inicia con la promulgación de la Ley $N^{\circ}$ 19300, Ley General Sobre Bases Generales del Medio Ambiente, hasta el momento en que, tres años más tarde, se implementa el Sistema de Evaluación de Impacto Ambiental (SEIA). El diseño de esta normativa se basó en la propuesta del Programa de las Naciones Unidas para el Medio Ambiente (PNUMA), pero no incluyó elementos relevantes, como el rango de ministerio de la institucionalidad o la figura de delito ambiental (Olivares-Gallardo, 2010). A la vez, evitó incidir en la zonificación ambiental y generó una debilidad regulatoria para el cumplimiento, que se vio favorecida además d e un seia que fomentó la "ventanilla única” y la aprobación de proyectos, lo que propició el incremento del flujo de inversión extranjera directa e indirecta, facilitado la política comercial activa de Chile (Tecklin et al., 2011).

A partir de 2010, con la dictación de la Ley $\mathrm{N}^{\circ} 20417$, que crea el Ministerio del Medio Ambiente (MMA), el Servicio de Evaluación Ambiental (SEA) y la Superintendencia del Medio Ambiente (SMA), se dio comienzo a las reformas a la institucionalidad ambiental, como respuesta a la agenda transversal del país con la ocDE y los Tratados de Libre Comercio suscritos (Bergamini et al., 2017; Olivares-Gallardo, 2010), así como a la influencia de los movimientos sociales locales (Tecklin et al., 2011), con lo que se inició un tercer periodo. Dos años más tarde se dictó la Ley N 20600 y se crearon los Tribunales Ambientales, como vehículo para el acceso a una justicia ambiental más equitativa. Entre las reformas más importantes del sector, se añadió el rol fiscalizador y regulatorio y la potestad sancionatoria y normativa, funciones que terminaron por recaer exclusivamente en la SMA.

En ese contexto, el mMa, la sma, el sea y los Tribunales Ambientales son los principales organismos del sector ambiental en Chile, con un rol articulador de carácter técnico-normativo para garantizar el desarrollo económico del país de forma sustentable. Con esta finalidad, el proceso se inicia con el SEA, entidad que evalúa y certifica los proyectos de inversión a través de la aprobación de las Resoluciones de Calificación Ambiental (RCA) en el marco del Sistema de Evaluación de Impacto Ambiental (SEIA). El sEIA es un "procedimiento regulado que establece los plazos, etapas y condiciones de la evaluación ambiental de proyectos de inversión públicos o privados que deben ajustarse a lo establecido en la normativa ambiental vigente" (Lira, 2017, p. 8). Hasta 2019, ingresaron al sEIA en total 9.426 proyectos, equivalentes a una inversión total de 467.007,3 millones de dólares. Más allá de las nuevas regulaciones establecidas, solo entre los ańos 2013 y 2019 ingresaron a evaluación 6.446 proyectos, equivalentes a más de la mitad del monto de inversión total. En este mismo periodo se aprobó solo el 48,1\% de proyectos ingresados. Según la clasificación del SEA, los sectores productivos más vinculados a la exportación, que tienen las mayores tasas de aprobación, son pesca y acuicultura $(52,1 \%)$, 
minería $(51,9 \%)$, instalaciones fabriles $(45,7 \%)$, forestal $(47,2 \%)$ y agropecuario (39,1\%) (sEA, 2019).

Una vez aprobado el proyecto de inversión, la SMA ejecuta, organiza y coordina el seguimiento y fiscalización de las RCA, de los Planes de Prevención y/o de Descontaminación Ambiental, de las Normas de Calidad Ambiental y Normas de Emisión, y de los Planes de Manejo cuando corresponda, y de todos aquellos otros instrumentos de carácter ambiental que establezca la Ley (Título I, Art. $2^{\circ}$, Ley $\mathrm{N}^{\circ}$ 20417, 2010). La sma también administra el Sistema Nacional de Información de Fiscalización Ambiental (SNIFA), sistema de acceso público que contiene antecedentes y datos en materia de fiscalización ambiental (Título II, Art. 30 Ley $\left.\mathrm{N}^{\circ} 20417,2010\right)$. Si la sma identifica un incumplimiento a cualquiera de los instrumentos de gestión mencionados, inicia un Procedimiento Sancionatorio al titular del proyecto. Este proceso puede culminar en una sanción aplicable o en la absolución del cargo, según la naturaleza de los hallazgos. De esta forma, el trabajo de estas instituciones se articula frente un mismo objetivo: el desarrollo sustentable (Ley $\mathrm{N}^{\circ}$ 19300, 2011).

Así, en los últimos cuarenta años, la economía de Chile ha crecido significativamente desde un PBI per cápita de 2.540 USD en 1980 hasta 14.984 USD en 2019 (Banco Mundial, 2019). Este modelo económico se ha sostenido fuertemente en el comercio internacional, especialmente en la exportación de bienes y servicios (Agosin, 1999; Ministerio de Relaciones Exteriores [MINReL], 2018; oECD/un, 2018). En los últimos cinco años, el comercio ha aportado, en promedio, con el $57 \%$ del PBi nacional. Solo las exportaciones representan el 28,7\% del PBI total para este mismo periodo (Banco Mundial, 2019). Sin embargo, es importante mencionar que, a partir del 2007, la representación de este sector en el PBI nacional ha ido disminuyendo de $45,1 \%$ a $28,8 \%$ en 2019 . En cuanto a los principales bienes de exportación, "Chile es el mayor productor de cobre del mundo y representa más de un tercio de las reservas totales mundiales. También es el principal productor mundial de yodo, renio, y litio (Chile representa el 63,2\%, 50\% y 39\% de la producción mundial, respectivamente)" (oeCD/un, 2018, p. 24).

La columna vertebral de la economía del país está constituida por sus recursos minerales, que representan el mayor activo natural de capital del país (Comisión Chilena del Cobre [Cochilco], 2013). Esta dependencia se acentuó mucho en los años setenta, cuando los metales y minerales representaban el 89,3\% del total de exportaciones. En los últimos cinco años, el 51,5\% del total de exportaciones ha sido de productos mineros (Aduanas Chile, 2020). Esta cifra ha ido disminuyendo, gracias a una estrategia política y económica del Estado para promover la diversificación de las exportaciones a través de la firma de Tratados de Libre Comercio (Wehner, 2011). Así, exportaciones no tradicionales, como productos manufacturados, agropecuarios y alimentarios, han ido creciendo en los últimos años (Cochilco, 2019). No obstante, el cobre sigue siendo el producto bandera del país. En 2019, a pesar de la guerra comercial entre China y Estados Unidos, principales socios comerciales de Chile, el 40,4\% de exportaciones mineras fue de cobre, y el $48,7 \%$ de minerales de cobre y sus concentrados (Aduanas Chile, 2020). 
Según Wehner (2011), Chile tiene una de las políticas más agresivas a nivel mundial para la promoción de Tratados de Libre Comercio (TLC). Tras estas políticas se esconden motivos económicos y políticos fuertemente impulsados por los grupos exportadores cooptados por el gobierno, una cooperación que ha superado a los grupos proteccionistas y ha permitido sentar la base del crecimiento económico del país (Wehner, 2011). Si bien los TLC contienen cláusulas para obligar a las partes a respetar los estándares ambientales mínimos, los mecanismos de aplicación de estas obligaciones en materia ambiental, según sostiene Grunni (2020), son vagos y poco prescriptivos. Así, entonces, la dinámica y evolución de la institucionalidad ambiental de Chile desde el enfoque de la economía neoclásica ha sido sentar las bases de un crecimiento económico de la mano de la mitigación del deterioro ecológico y de la preservación y recuperación de sus recursos naturales (Agosin, 1999; OCDE, 2016).

\section{Metodología}

Para el desarrollo de este artículo se asume que los montos de las infracciones a la normativa ambiental (resoluciones de calificación ambiental, normas de emisión, etcétera) constituyen una valoración de las externalidades generadas por los agentes económicos productivos.

La identificación de la actividad que generó la infracción, así como el país de origen de los capitales de la empresa o el destino de las exportaciones, permiten conocer si existe influencia del modelo de desarrollo del país en el deterioro del medioambiente y el origen de dicha condición. De esta forma, para el desarrollo de este trabajo se ha utilizado un enfoque lógico-inductivo a partir de las observaciones realizadas a los datos e información disponible de las variables mencionadas (Dávila Newman, 2006). En la Figura 1 se resume el diseño de la investigación realizada.

\section{FIGURA I | Diseño de la investigación bajo un enfoque lógico-deductivo}

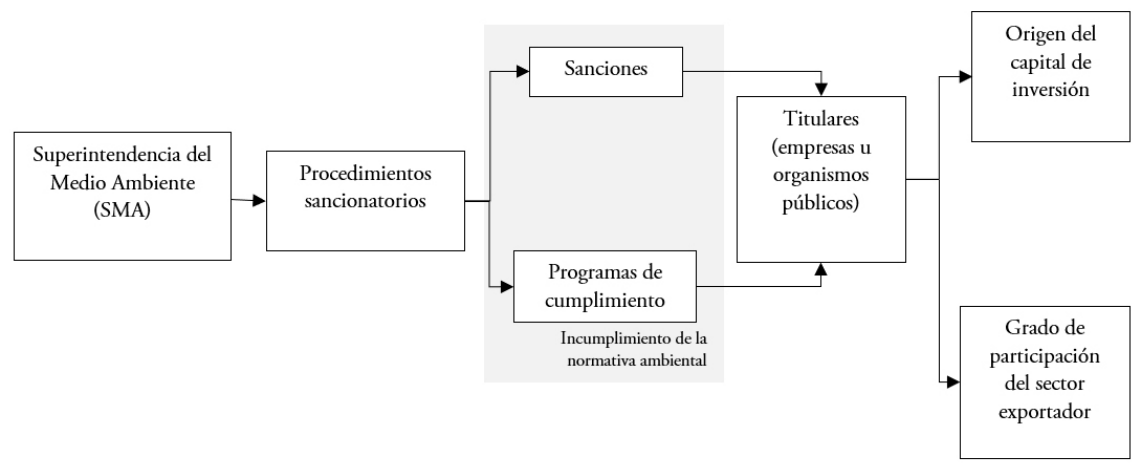

FUENTE: ELABORACIÓN PROPIA 
Para entender el diseño de la investigación, es importante tener presente que, al igual que un procedimiento administrativo general, una vez iniciado un Procedimiento Sancionatorio (PS) por la SMA, se continúa con una etapa de investigación plasmada en la formulación de cargos, cuyo contenido puede modificarse mediante la reformulación o ampliación de los mismos. Tras el descargo del presunto infractor, el proceso culmina con una resolución que absuelve o señala la sanción aplicable (Mallea, 2014). A partir de ello, interesan dos caminos que sigue un ps: el primero, referido exclusivamente a la sanción por multa como tal; y el segundo, a un mecanismo amparado en la Ley Orgánica de la SMA, mediante el cual se faculta al infractor la posibilidad de presentar un Programa de Cumplimiento (PDC), siempre y cuando haya aceptado los cargos una vez iniciado el ps, para regresar al estado de cumplimiento ambiental; y en caso de que este sea aprobado, el ps se suspende (Art. 2º Ley N²0417, 2010).

En ese contexto, son de interés para este trabajo los siguientes factores:

1. Los montos por sanciones, que corresponden a las penalidades impuestas por la SMA, las que se clasifican en función de la gravedad, y que corresponden a amonestación por escrito para infracciones leves; multas en Unidades Tributarias Anuales (UTA), entre 1 y 10.000 UTA según la gravedad de la infracción; la clausura temporal o definitiva del proyecto; y la revocación de la Resolución de Calificación Ambiental (RCA), estas dos últimas para infracciones graves y gravísimas (Título III, Art. 38², Ley No 20417, 2010).

2. Los PDC que reflejan los costos indirectos asumidos por el "contaminador" para regresar al estado de cumplimiento de la normativa ambiental, ya que contienen las medidas adoptadas para reducir o eliminar los efectos negativos generados por el incumplimiento detectado (Mallea, 2014).

En función de lo anterior, se construyó una base de datos de los ps a partir de la información disponible en el SNIFA de la SMA para el periodo 2013-2019. Dentro de la información disponible se encontró los ps iniciados a empresas, personas naturales, jurídicas e incluso al mismo Estado, que infringieron algún instrumento de gestión ambiental definido por ley, y otra serie de informaciones para su clasificación. Para el lapso en análisis, el universo total de fiscalizaciones ambientales registradas es de 24.838, de las cuales se desprenden 1.077 ps.

Sobre los 1.077 casos registrados se generó una indagación respecto de los orígenes de los capitales, a partir de la identificación de los propietarios de los titulares de los proyectos sancionados, lo que permitió vincular la infracción al país de origen de los capitales. En este caso, la búsqueda se inició en la información disponible en la web de cada empresa (páginas en donde se indica la procedencia de los capitales). Con posterioridad a ello se priorizaron fuentes relacionadas con la economía, finanzas y datos comerciales. En un segundo grupo, se realizó una búsqueda generalizada en páginas similares de otros países. La búsqueda concluye al momento de obtener la información del país de procedencia del capital de ese holding. Muchas compañías tenían más de un país como capital de origen y diversas proporciones de participación; en dicho contexto, el análisis consideró la totalidad de países que podían componer los capitales de una empresa, no así la proporción 
de participación, dividiendo los montos de multas de forma proporcional entre el total de países involucrados.

Por otro lado, para hacer el análisis desde los sectores económicos involucrados, dado que muchas empresas tienen como capital de origen Chile y lo interesante era saber cuál era su destino, se procedió a utilizar la clasificación de los sectores económicos del SNIFA, a fin de seleccionar aquellos más vinculados a la exportación de recursos minerales y no minerales, y contrastarlos con los datos de las exportaciones chilenas y el origen de los capitales publicados por el Banco Central de Chile y el Banco Mundial. Lo anterior permite establecer relaciones entre la matriz productiva del país, las empresas que incumplen la normativa ambiental y la cuantificación de las infracciones.

Para el análisis de las bases de datos se utilizó generalmente estadística descriptiva, ya que esta es suficiente para evidenciar las relaciones que se pretenden argumentar en el artículo. Los montos fueron trabajados en dólares estadounidenses. En relación con esto último, en el SNIFA los montos por multas se encontraban en Unidades Tributarias Anuales (UTA), las cuales fueron convertidas a dólares, considerando la información del Servicio de Impuestos Internos con un valor UTA para diciembre de 2019 de 595.476 pesos chilenos y un valor dólar para el 30 de diciembre de 2019 de 744,62 pesos chilenos.

Es importante tener presente que la principal diferencia de este enfoque respecto de otros que solo utilizan un componente ambiental (esencialmente emisiones atmosféricas), es que permite incorporar en el análisis la totalidad de los tipos de impactos ambientales, independientemente de si se trata de contaminación al agua, corta de vegetación o daño al patrimonio cultural, en una unidad de medida común: la sanción o gasto monetario en infracciones. Por lo tanto, esta unidad de medida representa una vía alternativa para detectar no solo el incumplimiento de normativas ambientales, sino, además, la afectación en general de la calidad ambiental del país. Claramente este enfoque tiene algunas limitaciones: el valor no necesariamente representa el monto adecuado para arreglar el dańo provocado y volver al estado anterior, entre otros. Sin embargo, el enfoque de esta investigación permite hacer comparaciones a partir de una medida común.

Así, la metodología propuesta en este estudio no plantea utilizar técnicas econométricas para explicar un fenómeno, sino más bien pone en valor la existencia de nuevos datos e indicadores como producto de la reforma a la institucionalidad ambiental. El foco es puesto en la fiscalización y sanción que podrían ser utilizados en el futuro para estudios más profundos o comparativos entre países, si se avanza en el establecimiento de los estándares normativos adecuados.

\section{Resultados}

Análisis de la relación entre los sancionatorios por incumplimiento ambiental y los capitales de origen de la inversión

En el periodo analizado, entre 2013 y 2019, la sMA inició 1.077 procedimientos sancionatorios, de los cuales 518 finalizaron en PDC, 348 en multas, y 211 se 
encuentran en otros estados, ${ }^{1} \sin$ haber llegado a multa o PDC. Debido a ello, se considera para el análisis los ps finalizados en PDC, en multas, más 26 casos que se contabilizan en PDC y multas, pues - de acuerdo con el Art. $42^{\circ}$ de la Ley $\mathrm{N}^{\circ}$ 20417 - en caso de detectarse que no se da fiel cumplimiento al primero, se reinicia el sancionatorio. De esta forma, se analizan en total 892 casos.

En relación con los montos equivalentes de los procedimientos sancionatorios, es posible ver cómo a la fecha se acumulan cerca de 426.000.000 usD en los cinco años de análisis, donde el mayor monto corresponde a PDC, con 325.000 .000 USD (76\%), y luego a las sanciones propiamente tales, con 101.000 .000 usD (24\%). Una síntesis de lo anterior se observa en la Figura 2.

\section{FIGURA 2 Procedimientos sancionatorios abiertos por la SMA que han finalizado en multas o Programas de Cumplimiento y montos involucrados}

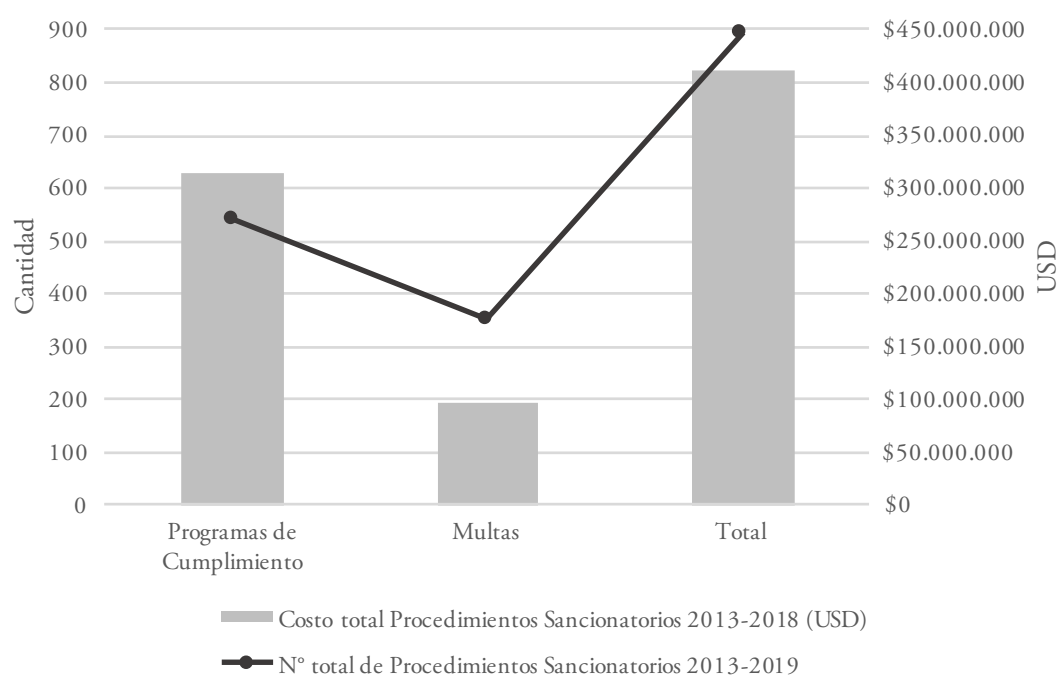

FUENTE: ELABORACIÓN PROPIA, SOBRE LA BASE DE DATOS DE LA SMA (2O2O)

Respecto a la cantidad de sancionatorios por sector económico según la clasificación del SNIFA, la mayor participación, con un 32,9\%, corresponde al sector de equipamiento, seguido con un $14,1 \%$ para agroindustrias, $8,8 \%$ en pesca y acuicultura, y $8,7 \%$ en minería, como se muestra en la Tabla 1 . Si el análisis se realiza por montos totales, la mayor participación corresponde al sector minería, con un $47 \%$ del total, es decir, cerca de los 193.000.000 usD; seguido por el sector energía, con 18,9\% equivalente a más de 77.000 .000 usD; y agroindustria, con 12,3\%, equivalente a más de 50.000.000 usD.

1 Los otros estados corresponden a 160 en curso, 3 a inconsistencias en el SNIFA, 29 suspendidos, 8 terminados en absolución y 11 terminados archivados. 
TABla I Participación de los sectores económicos en Chile en sancionatorios ambientales según cantidad y montos equivalentes, 2013-2019

\begin{tabular}{|c|c|c|c|c|}
\hline SECTOR ECONÓMICO & $\begin{array}{l}\text { CANTIDAD DE } \\
\text { SANCIONATORIOS }\end{array}$ & $\begin{array}{c}\text { PARTICIPACIÓN } \\
\text { POR } \\
\text { CANTIDAD DE } \\
\text { SANCIONATORIOS } \\
(\%) \\
\end{array}$ & $\begin{array}{c}\text { MONTO } \\
\text { EQUIVALENTE } \\
(\text { USD })^{*}\end{array}$ & $\begin{array}{c}\text { PARTICIPACIÓN } \\
\text { POR MONTO } \\
\text { EQUIVALENTE } \\
(\%)\end{array}$ \\
\hline Minería & 75 & 8,7 & 193.455 .381 & 47,0 \\
\hline Energía & 52 & 6,0 & 77.793 .152 & 18,9 \\
\hline Saneamiento ambiental & 57 & 6,6 & 28.305 .875 & 6,9 \\
\hline Forestal & 5 & 0,6 & 816.857 & 0,2 \\
\hline Instalaciones fabriles & 68 & 7,9 & 24.650 .936 & 6,0 \\
\hline Pesca y acuicultura & 76 & 8,8 & 19.712 .248 & 4,8 \\
\hline $\begin{array}{l}\text { Infraestructura de } \\
\text { transporte }\end{array}$ & 18 & 2,1 & 3.017 .888 & 0,7 \\
\hline Infraestructura portuaria & 11 & 1,3 & 2.682 .348 & 0,7 \\
\hline Agroindustrias & 122 & 14,1 & 50.644 .474 & 12,3 \\
\hline Inmobiliarias & 73 & 8,4 & 2.155 .551 & 0,5 \\
\hline Infraestructura hidráulica & 2 & 0,2 & 46.815 & 0,0 \\
\hline Otras categorías & 22 & 2,5 & 653.043 & 0,2 \\
\hline Equipamiento & 285 & 32,9 & 7.834 .999 & 1,9 \\
\hline Total & $866^{* *}$ & 100 & 411.769 .566 & 100 \\
\hline \multicolumn{5}{|c|}{ EL MONTO EQUIVALENTE TOTAL CORRESPONDE A LA SUMA DE LOS MONTOS DE PDC Y MULTAS } \\
\hline \multicolumn{5}{|c|}{$\begin{array}{l}\text { HAY } 23 \text { EXPEDIENTES QUE PRESENTAN PDC MÁS SANCIÓN (MULTA), MOTIVO POR EL CUAL SOLO } \\
\text { SE CONTABILIZA EN UNA CATEGORÍA, RESTANDO A LA CANTIDAD TOTAL DE } 892 \text { EXPEDIENTES, } \\
\text { LOS } 23 \text { EXPEDIENTES QUE SE DUPLICAN }\end{array}$} \\
\hline
\end{tabular}

$\mathrm{Al}$ menos el $70 \%$ de los montos equivalente a los sancionatorios ambientales se encuentra relacionado con los sectores económicos que representan la base de la exportación directa del país, siendo el más relevante la minería, con casi el 50\%. Si a la cifra anterior se le añaden los sectores que aportan a la base económica exportadora (energía, infraestructura de transporte, portuaria e hidráulica), llega hasta el 90\% de los montos, aproximadamente. En contraste, el sector equipamiento (relativo a actividades urbanas), si bien tiene el mayor número de procedimientos sancionatorios, solo equivale al $1,9 \%$ de las multas totales. Solo el sector de saneamiento ambiental (relativo al manejo de los residuos sólidos y líquidos) tiene montos relevantes, con el $6,9 \%$ del total. De esta forma, como análisis inicial se puede observar que los principales montos de multas ambientales que representan el deterioro o contaminación ambiental, se relacionan con la base económica exportadora del país.

Con respecto a los capitales de origen, en la Tabla 2 se presenta el ranking de países infractores por el total de infracciones en monto y cantidad. El podio lo lidera Chile, con 233.000.000 usD, seguido de Japón con 46.000.000 usD y Estados Unidos con 32.000.000 usD. En relación con la cantidad de procedimientos sancionatorios, el ranking lo lidera nuevamente Chile, con 810 sancionatorios, seguido por Estados Unidos con 29 y Espańa con 25. Es importante resaltar que, si bien Chile es el líder, 
la mayoría de los países que están en el ranking corresponden a economías desarrolladas del primer mundo, con algunas excepciones de países latinoamericanos, como Brasil o Argentina, cuyos montos equivalentes son menos significativos.

TABLA 2 Ranking de 15 primeros países por sancionatorios ambientales en montos y cantidad, 2013-2019

\begin{tabular}{|l|l|l|l|l|l|}
\hline $\mathbf{N}^{\circ}$ & \multicolumn{1}{|c|}{ PAÍ́ } & \multicolumn{1}{|c|}{$\begin{array}{c}\text { MONTO EQUIVALENTE } \\
\text { (USD) }\end{array}$} & \multicolumn{1}{|c|}{$\mathbf{N}^{\circ}$} & \multicolumn{1}{|c|}{ PAÍs } & \multicolumn{1}{c|}{$\begin{array}{c}\text { CANTIDAD DE } \\
\text { SANCIONES }\end{array}$} \\
\hline 1 & Chile & 232.649 .484 & 1 & Chile & 810 \\
\hline 2 & Japón & 46.225 .880 & 2 & Estados Unidos & 29 \\
\hline 3 & Estados Unidos & 32.169 .414 & 3 & Espańa & 25 \\
\hline 4 & Canadá & 24.343 .451 & 4 & Japón & 20 \\
\hline 5 & Reino Unido & 14.428 .746 & 5 & Canadá & 20 \\
\hline 6 & Suiza & 10.802 .406 & 6 & Italia & 14 \\
\hline 7 & Espańa & 9.309 .565 & 7 & Francia & 14 \\
\hline 8 & Italia & 8.446 .421 & 8 & Países Bajos & 14 \\
\hline 9 & Polonia & 8.445 .247 & 9 & Reino Unido & 12 \\
\hline 10 & Finlandia & 6.252 .895 & 10 & Noruega & 11 \\
\hline 11 & Francia & 4.864 .745 & 11 & Brasil & 10 \\
\hline 12 & Argentina & 2.940 .100 & 12 & Alemania & 10 \\
\hline 13 & Países Bajos & 2.445 .761 & 13 & Argentina & 8 \\
\hline 14 & Australia & 1.775 .601 & 14 & Suiza & 5 \\
\hline 15 & Bélgica & 1.470 .730 & 15 & Finlandia & 5 \\
\hline
\end{tabular}

Por otro lado, la distribución de los rankings presentados es heterogénea y muestra una realidad general, por lo que, a continuación, se analizan según sector económico. En la Tabla 3 se muestra la relación entre los sectores base de la exportación directa, los orígenes del capital y los montos equivalentes por infracciones. De esta forma, más allá de que las empresas chilenas lideren los rankings por sector, los capitales de origen varían considerablemente, siendo la inversión japonesa la que está en avanzada en el sector minería, la estadounidense en energía, la de Países Bajos en agroindustria, la argentina en la industria manufacturera, y la noruega en el sector de pesca y acuicultura.

La información presentada ha permitido una primera aproximación al origen de los capitales de inversión, destacándose que la mayoría corresponde a empresas chilenas, pero que varían según rubro de actividad, donde el sector exportador en general es el más importante en los montos de las multas. En dicho contexto se analizan a continuación las exportaciones de Chile, para dar cuenta de los destinos principales y relacionar esta situación con la matriz económica del país. 
TABLA 3 Montos equivalentes por sector económico y capitales de origen

\begin{tabular}{|c|c|c|c|}
\hline SECTOR ECONÓMICO & RANKING & PAÍS & EQUIVALENTE (USD) \\
\hline \multirow{4}{*}{ Minería } & 1 & Chile & 81.178 .133 \\
\hline & 2 & Japón & 44.578 .932 \\
\hline & 3 & Canadá & 22.118 .018 \\
\hline & 4 & Reino Unido & 14.022 .525 \\
\hline \multirow{4}{*}{ Energía } & 1 & Chile & 44.213 .624 \\
\hline & 2 & Estados Unidos & 21.440 .597 \\
\hline & 3 & Italia & 8.443 .544 \\
\hline & 4 & España & 1.313 .194 \\
\hline \multirow{4}{*}{ Agroindustrias } & 1 & Chile & 46.597 .467 \\
\hline & 2 & Países Bajos & 2.430 .577 \\
\hline & 3 & Brasil & 766.117 \\
\hline & 4 & Estados Unidos & 593.920 \\
\hline \multirow{4}{*}{ Instalaciones fabriles } & 1 & Chile & 14.425 .198 \\
\hline & 2 & Argentina & 2.938 .403 \\
\hline & 3 & Estados Unidos & 415.840 \\
\hline & 4 & España & 143.260 \\
\hline \multirow{4}{*}{ Pesca y acuicultura } & 1 & Chile & 18.858 .509 \\
\hline & 2 & Noruega & 691.488 \\
\hline & 3 & Japón & 139.757 \\
\hline & 4 & Estados Unidos & 22.493 \\
\hline
\end{tabular}

FUENTE: ELABORACIÓN PROPIA, SOBRE LA BASE DE DATOS DE LA SMA (2020)

\section{Análisis de las exportaciones por sectores económicos y país destino}

En el mismo periodo de análisis, las exportaciones chilenas han tenido como destino principal el continente asiático (50,8\%). Solo en 2019 se observó una ligera reducción, producto de la guerra comercial entre China y Estados Unidos (Banco Central de Chile, 2020). El segundo destino comercial por zona geográfica es América del Norte, con el 16,9\% de exportaciones. Las exportaciones a Europa para este mismo periodo representaron un total del 15,4\%, mientras Oceanía apenas representa el $0,8 \%$. En la Tabla 4 se encuentra el ranking de los primeros quince países destino de las exportaciones chilenas, que en conjunto dan cuenta de más del $80 \%$ del total de exportaciones entre los ańos 2013 y 2019.

Con respecto a las exportaciones por sector económico, es importante poner de relieve el sector minero, debido a la participación representativa que tiene en el análisis de sancionatorios. Hasta 2019, el 75,4\% de envíos en exportaciones solo de cobre, tuvieron como destino los países del continente asiático (China recibió el $50,8 \%$ de exportaciones totales de cobre, seguido de Japón con 10,6\%). En América del Norte, Estados Unidos es el principal país destino del cobre chileno (8,5\%); y en la región económica europea, Alemania, España y Francia representan el 6,1\% de exportaciones totales de cobre (Cochilco, 2019). En el periodo de análisis de este estudio, China, Japón, Corea del Sur y Estados Unidos concentran casi el 70\% 
del total de exportaciones minerales desde Chile, convirtiéndose en sus principales socios comerciales en este sector (Aduanas Chile, 2020).

TABla 4 Ranking de países según el destino de las exportaciones de Chile en montos y participación en el total de exportaciones, 2013-2019 (en USD FOB y porcentajes)

\begin{tabular}{|r|l|c|c|}
\hline $\mathbf{N}^{\circ}$ & \multicolumn{1}{|c|}{ PAÍs DESTINO } & $\begin{array}{c}\text { EXPORTACIONES TOTALES } \\
\text { (USD FOB })\end{array}$ & $\begin{array}{c}\text { PARTICIPACIÓN EN } \\
\text { EXPORTACIONES TOTALES } \\
(\%)\end{array}$ \\
\hline 1 & China & 137.545 .952 & 28,2 \\
\hline 2 & Estados Unidos & 65.360 .576 & 13,4 \\
\hline 3 & Japón & 44.967 .873 & 9,2 \\
\hline 4 & Corea del Sur & 30.178 .268 & 6,2 \\
\hline 5 & Brasil & 24.357 .986 & 4,9 \\
\hline 6 & Países Bajos & 12.913 .561 & 2,6 \\
\hline 7 & India & 12.613 .548 & 2,6 \\
\hline 8 & Perú & 12.126 .082 & 2,5 \\
\hline 9 & Taiwán & 10.171 .425 & 2,1 \\
\hline 10 & Espańa & 10.124 .500 & 1,9 \\
\hline 11 & Bolivia & 9.297 .691 & 1,8 \\
\hline 12 & México & 8.965 .225 & 1,7 \\
\hline 13 & Canadá & 8.265 .081 & 1,6 \\
\hline 14 & Italia & 7.832 .790 & 1,4 \\
\hline 15 & Francia & 6.748 .331 & 82,2 \\
\hline Total & & 401.468 .890 & \\
\hline
\end{tabular}

FUENTE: ELABORACIÓN PROPIA, SOBRE LA BASE DE DATOS DEL SERVICIO NACIONAL DE ADUANAS (2O2O)

El consolidado total de exportaciones por país destino según los sectores SNIFA se presenta en la Tabla 5. En la exportación de productos no minerales, los principales productos de exportación del sector de agroindustrias tuvieron como destino Estados Unidos, China y Japón. Por otro lado, la salmonicultura es la actividad más representativa en el sector de pesca y acuicultura: aproximadamente el 76,2\% de los productos del mar para exportación son de salmón. Países como Estados Unidos, Japón y Brasil son los principales mercados del salmón chileno. En los demás sectores la participación de estos países es similar. En el sector de instalaciones fabriles se observa una mayor exportación de productos químicos, bebidas y de la industria metálica a países latinoamericanos como Bolivia, Perú, Brasil, Paraguay, Argentina y México, que en conjunto suman más del $40 \%$ del total de exportaciones fabriles. 
TABLA 5 Exportaciones de Chile según sector económico y participación por país destino, 2013-2019

\begin{tabular}{|c|c|c|c|c|}
\hline $\begin{array}{c}\text { SECTOR } \\
\text { ECONÓMICO }\end{array}$ & $\mathbf{N}^{\circ}$ & PAÍS DESTINO & $\begin{array}{c}\text { EXPORTACIONES } \\
\text { TOTALES } \\
\text { (USD FOB) } \\
\end{array}$ & $\begin{array}{c}\text { PARTICIPACIÓN EN } \\
\text { EXPORTACIONES } \\
\text { TOTALES }(\%) \\
\end{array}$ \\
\hline \multirow{11}{*}{ Minería } & 1 & China & 10.314 .773 & 42,4 \\
\hline & 2 & Japón & 27.757 .650 & 10,7 \\
\hline & 3 & Corea del Sur & 22.573 .368 & 8,7 \\
\hline & 4 & Estados Unidos & 20.764 .487 & 4,3 \\
\hline & 5 & India & 11.112 .708 & 2,8 \\
\hline & 6 & Brasil & 10.943 .405 & 8,0 \\
\hline & 7 & Taiwán & 7.400 .957 & 4,2 \\
\hline & 8 & Espańa & 6.320 .183 & 1,9 \\
\hline & 9 & Canadá & 4.825 .088 & 2,4 \\
\hline & 10 & Italia & 4.654 .014 & 1,8 \\
\hline & \multicolumn{2}{|l|}{ Total } & 226.666 .633 & 87,1 \\
\hline \multirow{11}{*}{ Agroindustrias } & 1 & Estados Unidos & 32.839 .414 & 22,1 \\
\hline & 2 & China & 16.530 .302 & 11,1 \\
\hline & 3 & Japón & 13.031 .378 & 8,8 \\
\hline & 4 & Brasil & 9.179 .920 & 6,2 \\
\hline & 5 & Países Bajos & 5.623 .101 & 3,8 \\
\hline & 6 & Perú & 4.911 .506 & 3,3 \\
\hline & 7 & México & 4.694 .348 & 3,2 \\
\hline & 8 & Corea del Sur & 4.584 .145 & 3,1 \\
\hline & 9 & Rusia & 4.557 .817 & 3,1 \\
\hline & 10 & Reino Unido & 4.141 .740 & 2,8 \\
\hline & \multicolumn{2}{|l|}{ Total } & 100.093 .671 & 67,4 \\
\hline \multirow{11}{*}{$\begin{array}{l}\text { Pesca y } \\
\text { acuicultura }\end{array}$} & 1 & Estados Unidos & 10.113 .691 & 34,8 \\
\hline & 2 & Japón & 4.717 .443 & 16,2 \\
\hline & 3 & Brasil & 3.818 .575 & 13,1 \\
\hline & 4 & Rusia & 2.028 .929 & 7,0 \\
\hline & 5 & China & 1.997 .928 & 6,9 \\
\hline & 6 & México & 698.459 & 2,4 \\
\hline & 7 & Corea del Sur & 662.287 & 2,3 \\
\hline & 8 & Alemania & 488.858 & 1,7 \\
\hline & 9 & Tailandia & 395.519 & 1,4 \\
\hline & 10 & Francia & 366.580 & 1,3 \\
\hline & \multicolumn{2}{|l|}{ Total } & 25.288 .268 & 87,0 \\
\hline \multirow{11}{*}{$\begin{array}{l}\text { Instalaciones } \\
\text { fabriles }\end{array}$} & 1 & Estados Unidos & 10.592 .595 & 12,7 \\
\hline & 2 & Bolivia & 8.775 .008 & 10,5 \\
\hline & 3 & Perú & 7.752 .285 & 9,3 \\
\hline & 4 & Brasil & 7.096 .886 & 8,5 \\
\hline & 5 & Japón & 4.022 .000 & 4,8 \\
\hline & 6 & China & 3.816 .449 & 4,6 \\
\hline & 7 & Paraguay & 3.807 .992 & 4,6 \\
\hline & 8 & Argentina & 3.515 .329 & 4,2 \\
\hline & 9 & Países Bajos & 3.076 .696 & 3,7 \\
\hline & 10 & México & 2.572 .605 & 3,1 \\
\hline & \multicolumn{2}{|l|}{ Total } & 52.455 .240 & 62,8 \\
\hline
\end{tabular}

FUENTE: ELABORACIÓN PROPIA, SOBRE LA BASE DE DATOS DEL BANCO CENTRAL DE CHILE (2O2O) 
En este análisis no se incluyó el sector forestal, por tener una representación marginal en el análisis de procedimientos sancionatorios. Sin embargo, es importante precisar que China (32,3\%), Estados Unidos (11,2\%), Países Bajos (5,6\%), Perú $(3,4 \%)$ e Italia $(2,9 \%)$ son los principales países destino de productos forestales, tanto de madera como de celulosa y papel (Banco Central de Chile, 2020).

\section{Discusiones}

La economía basada en el libre comercio ha tenido como característica central la disminución de barreras arancelarias del comercio internacional de bienes y servicios. No obstante, hoy resulta paradójico afirmar que este modelo es "recíprocamente beneficioso para todos los países”, según los principales fundamentos de las bases teóricas del comercio internacional de Adam Smith y David Ricardo. Lo cierto es que la realidad de los diversos mercados, especialmente de las economías emergentes, es mucho más compleja cuando se trata de garantizar una asignación eficaz de los recursos. De esta forma, en condiciones de competencia desigual, o cuando los indicadores del mercado no reflejan los costos y beneficios sociales reales, surgen efectos indirectos, como las externalidades negativas, que suelen estar relacionadas con la mala gestión de explotación de los recursos naturales (омC, 2004, 2010).

Del caso de estudio, después de Chile, los capitales de inversión extranjera que tienen más infracciones ambientales se encuentran en los 30 primeros países con mejor desempeño ambiental según el Índice de Desempeño Ambiental (EPI, por siglas en inglés) de la Universidad de Yale (2020). Cabe resaltar que el EPI es una métrica de las políticas ambientales de 180 países a nivel mundial, entre cuyas primeras posiciones destacan los países líderes en sostenibilidad. En la Tabla 6 se observa que, mayormente, los capitales de inversión europeos se encuentran dentro de los 20 primeros puestos en el ranking EPI y entre los 10 países más infractores en Chile. A esta lista se añade Japón (EPI=12) como el único país del continente asiático con capitales de inversión en Chile; y de América del Norte, Canadá y Estados Unidos, el primero con un ranking EPI mejor que el segundo, pero ambos con 20 y 29 infracciones ambientales, respectivamente. De igual manera, es importante señalar que Suiza, Finlandia y Reino Unido, países con un desempeño ambiental entre los 10 primeros a nivel mundial, tienen la mayor tasa de infracciones según el monto por infracción, después de Polonia.

Respecto a la relación entre la exportación de recursos naturales por país destino, China, el principal socio comercial de Chile (Aduanas Chile, 2020; oec, 2018), es también uno de los países con el peor desempeño ambiental (EPI=120), solo superado por India (EPI=168), que en conjunto tienen una participación en el 30,7\% del total de exportación. En el otro extremo se encuentran los países europeos con mejor índice EPI, pero que apenas representan el 7,7\% del total de exportaciones. La tercera región económica más importante para Chile es América Latina, con una participación en el 11,2\% de este sector. Sin embargo, es esta también una de las regiones con un menor desempeño ambiental a nivel global. Países como Perú, Bolivia, Brasil y México tienen un índice EPI muy por debajo del de Chile. 
TABLA 6 | Relación entre el ranking EPI, origen de los capitales de la inversión y los sancionatorios ambientales en cantidad y monto, 2013-2019

\begin{tabular}{|l|l|c|c|}
\hline $\begin{array}{c}\text { RANKING } \\
\text { EPI }\end{array}$ & ORIGEN DE LA INVERSIÓN & $\begin{array}{c}\text { CANTIDAD DE } \\
\text { INFRACCIONES }\end{array}$ & $\begin{array}{c}\text { MONTO POR SANCIÓN } \\
\text { (USD) }\end{array}$ \\
\hline 3 & Suiza & 5 & 2.160 .481 \\
\hline 4 & Reino Unido & 12 & 1.202 .395 \\
\hline 5 & Francia & 14 & 347.482 \\
\hline 6 & Australia & 4 & 443.900 \\
\hline 7 & Finlandia & 5 & 1.250 .579 \\
\hline 9 & Noruega & 11 & 62.863 \\
\hline 10 & Alemania & 10 & 106.127 \\
\hline 11 & Países Bajos & 20 & 815.254 \\
\hline 12 & Japón & 25 & 2.311 .294 \\
\hline 14 & Espańa & 3 & 372.383 \\
\hline 15 & Bélgica & 20 & 490.243 \\
\hline 20 & Canadá & 14 & 1.217 .173 \\
\hline 20 & Italia & 29 & 603.316 \\
\hline 24 & Estados Unidos & 1 & 1.109 .290 \\
\hline 37 & Polonia & 810 & 8.445 .247 \\
\hline 44 & Chile & 4 & 287.222 \\
\hline 50 & Colombia & 10 & 186.551 \\
\hline 54 & Argentina & Basil & 367.513 \\
\hline 55 & Bras & 121.560 \\
\hline
\end{tabular}

FUENTE: ELABORACIÓN PROPIA, SOBRE LA BASE DEL ÍNDICE EPI DE LA UNIVERSIDAD DE YALE (2O2O) Y LOS DATOS DE LA SMA (2O20)

De este primer análisis se podría afirmar un distanciamiento más claro del estudio respecto de la teoría de los paraísos de la contaminación citada por Temkin Yebwad et al. (2018). Sin embargo, es necesario complementar estos hallazgos con evidencia sólida en otros países de Latinoamérica en similares condiciones. Esto podría representar una oportunidad para la Red Sudamericana de Fiscalización y Cumplimiento Ambiental (REDLAFICA), una organización integrada por instituciones públicas que ejercen funciones de fiscalización ambiental en América Latina, de la que Chile forma parte con la SMA. La REDlafica tiene en su Plan Estratégico 2019-2021 la elaboración de indicadores a nivel regional que podrían dar soporte a líneas de investigación a partir de este estudio (REDlafiCA, 2019).

Asimismo, el principal desafío está en encontrar una prevalencia de la ventaja competitiva sobre la ventaja comparativa en la toma de decisión de una industria para ubicarse en una determinada región (Temkin Yedwab et al., 2018). De esta forma, se debería considerar en el caso de Chile, como mayor productor de cobre, la localización de los yacimientos, si el cumplimiento ambiental con otros países productores de cobre es similar, o si las normativas existentes influyen en la preferencia de ciertos capitales para invertir en Chile, por sobre otros países. Un ideal en ese sentido sería comparar Chile con Perú, los dos principales exportadores de cobre del mundo (CEPAL, 
2018, fig. 12c), y evidenciar si la normativa ambiental ejerce alguna influencia en la preferencia de una compañía por instalarse en uno u otro país.

Por otra parte, respecto a la existencia de una curva ambiental de Kuznets (CAK) para Chile según los efectos del comercio, los datos no son suficientes para hacer un análisis fundado, puesto que se requiere de series de tiempo más largas. Por lo tanto, en caso de mantenerse estos indicadores, y en caso de existir cambios, ya sea en la base económica o en las normativas ambientales, se podrá analizar y comparar los periodos para confirmar dicha teoría. No obstante, es importante tener presente lo señalado por Zilio (2015), quien sostiene que el efecto escala de la CAK podría redireccionarse gracias al crecimiento del comercio internacional. Es decir, Chile podría estar relocalizando sus flujos comerciales más contaminantes a otros países de Latinoamérica con políticas ambientales más débiles. Esto último también sirve de sustento para la teoría de los "paraísos de la contaminación", para lo cual es necesario ańadir otras variables de análisis, como las interrelaciones entre la distribución de ingresos, los patrones de crecimiento local y los patrones de crecimiento poblacional, sin dejar de lado la relevancia del marco institucional en estos procesos (Zilio, 2015).

Finalmente y en relación con la especialización de industrias contaminantes y la aplicación de las teorías de Prebisch (Pérez-Rincón, 2006; Torres Preciado \& Polanco Gaytán, 2016), los resultados evidencian que existe una concentración en la industria minera, favorecida por la disponibilidad de esos recursos naturales, generándose una exportación hacia países procesadores de materias primas y dejando en el país afectaciones concretas al medioambiente. Esto último permite poner en agenda el impacto que tienen las políticas agresivas de libre comercio en Chile (Wehner, 2011) sobre el medioambiente. "La liberalización del comercio conduce a la especialización, y los países que se especializan en bienes menos contaminantes tendrán un medio ambiente más limpio" (Ederington et al., 2004, p. 1). Así, en el proceso de transformación social, política y económica que viene atravesando Chile, es momento de abrir la discusión sobre los efectos directos de la liberalización comercial en la composición de las industrias en el país.

\section{Conclusiones}

La economía chilena tiene sus pilares en el libre comercio, y se encuentra principalmente dedicada a la exportación de sus recursos naturales, modelo que ha permitido un crecimiento sostenido del país en los últimos veinticinco años. No obstante, la dependencia de unas cuantas materias primas puede generar un escenario negativo debido a malas prácticas ambientales por los dueńos de los principales proyectos de inversión implicados. Esto puede conllevar a una mayor presión sobre los recursos y, por lo tanto, al deterioro de la capacidad natural de los ecosistemas de seguir proveyendo diversos servicios ambientales. Peor aún, en términos económicos, como mencionan Ffrench-Davis y Díaz (2019), esto podría generar un rendimiento decreciente en los niveles de producción y exportación, especialmente en los sectores forestal, salmonero, frutícola y vitivinícola. 
Se comprueba que los rubros con mayor formulación de cargos corresponden a actividades de exportación; así, los sectores minero, agropecuario, fabril y pesca han pagado más que otros sectores (70\% del total aproximadamente), confirmando la primera hipótesis del estudio. Sin embargo, se descarta la segunda hipótesis, porque después de Chile, los capitales de inversión de Japón, Estados Unidos, Países Bajos, Argentina y Noruega lideran el ranking de países con más sancionatorios ambientales en monto y cantidad en los sectores minero, energético, agroindustrial, fabril y pesca, donde las principales compañías pagaron aproximadamente 411.000.000 USD, ya sea en PDC o en multas impuestas por daños ambientales en los últimos cinco ańos. Este resultado necesita un mayor análisis para poder determinar por qué Chile es el principal infractor ambiental. Si bien los demás países representan economías desarrolladas del primer mundo y se podría asumir que cuentan con mayor experiencia y tecnología para mitigar los impactos ambientales de sus actividades, los hallazgos de este estudio responden al análisis de nueva información con la que se no se contaba hace unos cinco ańos. Por lo tanto, sugerimos que se incorpore esta información en futuros estudios en la materia.

Por otro lado, el análisis de las exportaciones muestra, además, que la actividad económica también está influida por la matriz de explotación de recursos naturales, siendo China, Japón y Corea del Sur, en Asia, así como Estados Unidos y Brasil en América, los cinco primeros destinos comerciales, que totalizan poco más del $60 \%$. Por lo tanto, son las principales potencias económicas del mundo las que influyen en la matriz exportadora de Chile.

De esta forma, para el caso de estudio, se puede afirmar, inicialmente, la existencia de una "exportación de la contaminación", dado que se evidencia un deterioro ambiental producto del modelo económico, así como la influencia de grandes potencias o países desarrollados en esa condición. El avance en datos de multas y costos de recuperación ambiental, en Chile y otros países en vías de desarrollo, ayudará con el tiempo a una mejor comprensión de esta problemática, siendo clave el trabajo que la Red Latinoamericana de Fiscalización y Cumplimiento Ambiental (REDLAFICA, 20I9) está llevando a cabo en homologación de indicadores.

\section{Referencias bibliográficas}

Aduanas Chile. (2020). Anuario Estadístico 2019. Ministerio de Hacienda, Dirección Nacional de Aduanas Chile. https://www.aduana.cl/estadisticasCOMEX/anuario/2019/ anuario2019.html

Agosin, M. R. (1999). Comercio y crecimiento en Chile. Revista de la CEPAL, 68, 79-100. https:/www.cepal.org/es/publicaciones/12179-comercio-crecimiento-chile

Ávila-Fuenmayor, F. (2005). Neoliberalismo y globalización: de la racionalidad técnica a la relación sujeto-sujeto. Revista de Artes y Humanidades UNICA, 6(12), 89-100. https:// www.redalyc.org/pdf/1701/170121560005.pdf

Banco Central de Chile. (2020). Estadísticas Comercio Exterior. Banco Central de Chile. https:// si3.bcentral.cl/estadisticas/Principal1/Excel/SE/COMEX/excel.html 
Banco Mundial. (2019). Datos de comercio del Banco Mundial (\% of GDP) [página web]. Recuperado el 16 de junio de 2020. https://datos.bancomundial.org/indicador/ NE.TRD.GNFS.ZS?locations $=\mathrm{CL}$

Barton, J., Reyes, F., Galilea, S., Prieto, M. \& Álamos, P. (2007). El nuevo diseńo de la institucionalidad ambiental en Chile. En Camino al bicentenario. Propuestas para Chile (pp. 136-147). Pontificia Universidad Católica de Chile. https://politicaspublicas. uc.cl/wp-content/uploads/2015/02/el-nuevo-diseno-de-la-institucionalidadambiental-en-chile.pdf

Beck, U. (2008). Qué es la globalización? Falacias del globalismo, respuestas a la globalización. Trad. de B. Moreno \& R. Borrás. Paidós.

Bergamini, K., Irarrázabal, R., Monckeberg, J. C. \& Peréz, C. (2017). Fiscalización, sanción y control ambiental en Chile. Diagnóstico y propuestas para la Superintendencia del Medio Ambiente y tribunales ambientales. En Propuestas Para Chile 2018 (Cap. VI, pp. 167-198). Concurso Políticas Públicas 2017. https://politicaspublicas.uc.cl/wpcontent//uploads/2018/03/CAP-VI-Propuestas-para-Chile-2017.pdf

Carruthers, D. (2001). Environmental politics in Chile: Legacies of dictatorship and democracy. Third World Quarterly, 22(3), 343-358. https://doi.org/10.1080/01436590120061642

Catalán, H. (2015). Curva ambiental de Kuznets: implicaciones para un crecimiento sustentable. Economia Informa, 389, 19-37. https://doi.org/10.1016/s0185-0849(14)72172-3

Comisión Chilena del Cobre (Cochilco). (2013). Minería en Chile: impacto en regiones y desafíos para su desarrollo. Ministerio de Minería / Cochilco.

Comisión Chilena del Cobre (Cochilco). (2019). Anuario de Estadísticas del Cobre y otros Minerales 1999-2018 [Reporte estadístico]. Ministerio de Minería / Cochilco. https:// www.cochilco.cl/Lists/Anuario/Attachments/20/AE2019avance.pdf

Comisión Económica para América Latina y el Caribe (CEPAL). (2005). Políticas e iniciativas de aglomeración: lo normativo. En Aglomeraciones en torno a recursos naturales en América Latina y el Caribe: Políticas de articulación y articulación de politicas (pp. 107-128). Naciones Unidas / CEPAL / GTZ. https://repositorio.cepal.org/bitstream/ handle/11362/2447/1/S2005681_es.pdf

Comisión Económica para América Latina y el Caribe (CEPAL). (2018). Estudio Económico de América Latina y el Caribe 2018. Evolución de la inversión en América Latina y el Caribe: hechos estilizados, determinantes y desafios de politica. Naciones Unidas / CEPAL. https:// www.cepal.org/es/publicaciones/43964-estudio-economico-america-latina-caribe2018-evolucion-la-inversion-america

Dávila Newman, G. (2006). El razonamiento inductivo y deductivo dentro del proceso investigativo en ciencias experimentales y sociales. Laurus. Revista de Educación, 12(núm. ext. 2006), 180-205. https://www.redalyc.org/pdf/761/76109911.pdf

Davis, J. (1984). Environmental law and the export of pollution. Journal of Geography, 83(4), 154-158. https://doi.org/10.1080/00221348408980493

Ederington, J., Levinson, A. \& Minier, J. (2004). Trade liberalization and pollution havens. Advances in Economic Analysis \& Policy, 4(2). https://doi.org/10.2202/1538-0637.1330

Falconí, F., Burbano, R. \& Cango, P. (2016). La discutible curva de Kuznets. Documento de trabajo. Flacso-Ecuador.

Fermoso, P. (1997). Manual de economía de la educación. Narcea Ediciones. 
Ffrench-Davis, R. (2003). El experimento neoliberal: una síntesis crítica. En Entre el neoliberalismo y el crecimiento con equidad: Tres décadas de politica económica en Chile (pp. 81-114). (3a ed.). CEPAL/ LOM Ediciones. https://repositorio.cepal.org/bitstream/ handle/11362/1782/1/S330122F437E2003_es.pdf

Ffrench-Davis, R. \& Díaz, Á. (2019). La inversión productiva en el desarrollo económico de Chile: evolución y desafíos. Revista de la CEPAL, 127, 27-54. https://repositorio.cepal. org/bitstream/handle/11362/44571/1/RVE127_Ffrench-Davis.pdf

Furuoka, F. \& Lo, M. (2005). Japanese multinational corporations and the export of pollution: The case of Bukit Merah. Electronic Journal of Contemporary Japanese Studies. http:// www.japanesestudies.org.uk/articles/2005/FuruokaandChiun.html

Giljum, S. (2004). Trade, materials flows, and economic development in the south: The example of Chile. Journal of Industrial Ecology, 8(1-2), 241-261. https://doi. org/10.1162/1088198041269418

Gligo V., N. (2006). Estilos de desarrollo y medio ambiente en América Latina, un cuarto de siglo después. Series de la CEPAL - Medio Ambiente y Desarrollo, 126. Naciones Unidas I CEPAL https://repositorio.cepal.org/bitstream/handle/11362/5658/1/S0600341_ es.pdf

Grunni, G. (2020). The unsustainable lightness of enforcement procedures: environmental standards in the EU-Mercosur FTA. Blog Droit Européen, May, 1-4. https:// blogdroiteuropeen.com/2020/05/13/the-unsustainable-lightness-of-enforcementprocedures-environmental-standards-in-the-eu-mercosur-fta-by-giovanni-gruni/

Gudynas, E. (2010). Imágenes, ideas y conceptos sobre la naturaleza en América Latina. En L. Montenegro (Ed.), Cultura y naturaleza (pp. 267-292). Jardín Botánico de Bogotá José Celestino Mutis.

Gudynas, E. (2019). Desarrollo y límites al crecimiento económico: una polémica persistente. En P. García, J. Ordoñez \& R. Munck (Eds.), Desarrollo, sociedad, alternativas (pp. 252-279). Glasnevin Publishing.

Hall, D. (2009). Pollution export as state and corporate strategy: Japan in the 1970s. Review of International Political Economy, 16(2), 260-283. https://doi. org/10.1080/09692290802341173

Ianni, O. (1996). Las economías del mundo. En Teorías de la globalización (pp. 13-30). Siglo XXI editores / Centro de Investigaciones Interdiciplinarias en Ciencias y HumanidadesUniversidad Nacional Autónoma de México (CEIICH-unAm).

Jenkins, R. (2003). La apertura comercial ¿̨ha creado paraísos de contaminadores en América Latina? Revista de la CEPAL, 80, 85-100. https://doi.org/10.18356/cbba3fe8-es

Ley $N^{\circ} 19300$ sobre Bases Generales del Medio Ambiente-modificada por la Ley $N^{\circ} 20417$. (2011). http://bcn.cl/2f707

Ley $N^{\circ}$ 20417, Ley que crea el Ministerio, el Servicio de Evaluación Ambientaly la Superintendencia del Medio Ambiente. (2010). http://bcn.cl/2fade

Lira, J. (2017). Revisión y propuestas para el Sistema de Evaluación de Impacto Ambiental en Chile. Libertad y Desarrollo, Serie Informe Económico 267. https://lyd.org/wp-content/ uploads/2017/12/SIE-267-Revision-y-propuestas-para-el-Sistema-de-Evaluacion-deImpacto-Ambiental-en-Chile-Octubre17.pdf

Mallea, M. I. (2014). La potestad fiscalizadora y sancionatoria de la Superintendencia del Medio Ambiente en Chile. Revista de Derecho, (32), 135-156. 
Mari, C., Evans, M. J., Palmer, P. I., Jacob, D. J. \& Sachse, G. W. (2004). Export of Asian pollution during two cold front episodes of the TRACE-P experiment. J. Geophys. Res., 109(D15). https://doi.org/10.1029/2003JD004307

Márquez-Ortiz, L. E., Cuéstara-Sánchez, L. M., Cartay-Angulo, R. C. \& Labarca-Ferrer, N. J. (2020). Desarrollo y crecimiento económico: Análisis teórico desde un enfoque cuantitativo. Revista de Ciencias Sociales, 26(1), 233-253. https://dialnet.unirioja.es/ servlet/articulo?codigo $=7384417$

Meadwos, D. L., Randers, J. \& Meadwos, D. H. (1972). The future of nature. En L. Robin, S. Sörlin \& P. Warde (Eds.), The limits to growth (pp. 101-116). Yale University Press.

Meekosha, H. (2011). Decolonising disability: thinking and acting globally. Disability \& Society, 26(6), 667-682. https://doi.org/10.1080/09687599.2011.602860

Ministerio de Relaciones Exteriores (MINREL), Chile. (2018). Anuario de Exportaciones Chilenas 2018. Dirección General de Relaciones Económicas Internacionales (DIRECON) / ProChile.

Observatory of Economic Complexity (oEc). (2018). Chile (chl) Exports, imports, and trade partners. https://oec.world/en/profile/country/chl/

Olivares-Gallardo, A. (2010). El nuevo marco institucional ambiental en Chile. Revista Catalana de Dret Ambiental, 1(1), 1-23. https://doi.org/10.17345/rcda1039

Organisation for Economic Co-operation and Development / United Nations (oECD/ un). (2018). Production Transformation Policy Review of Chile: Reaping the benefits of new frontiers. OECD Development Pathways. OECD Publishing, Paris. https://doi. org/10.1787/9789264288379-en

Organización Mundial del Comercio (омc). (2004). Informe sobre el Comercio Mundial 2004. Análisis del vínculo entre el entorno normativo nacional y el comercio internacional. омс. https://www.wto.org/spanish/res_s/booksp_s/anrep_s/world_trade_report04_s.pdf

Organización Mundial del Comercio (омc). (2010). Informe sobre el Comercio Mundial 2010. El comercio de recursos naturales. OMc. https://www.wto.org/spanish/res_s/booksp_s/ anrep_s/world_trade_report10_s.pdf

Organización para la Cooperación y el Desarrollo Económicos (OCDE). (2016). Evaluaciones del desempeño ambiental: Chile, aspectos destacados 2016. http://oe.cd/epr

Pérez-Rincón, M. A. (2006). Colombian international trade from a physical perspective: Towards an ecological "Prebisch thesis". Ecological Economics, 59(4), 519-529. https:// doi.org/10.1016/j.ecolecon.2005.11.013

Pérez-Rincón, M. A. (2007). Comercio internacional y medio ambiente en Colombia: mirada desde la economía ecológica. Programa Editorial Universidad del Valle.

Pochanart, P., Wild, O. \& Akimoto, H. (2004). Air pollution import to and export from East Asia. En Intercontinental Transport of Air Pollution. The Handbook of Environmental Chemistry (pp. 99-130). Springer-Verlag. https://doi.org/10.1007/b94525

Pörtner, H.-O., Roberts, D. C., Masson-Delmotte, V., Zhai, P., Tignor, M., Poloczanska, E., Mintenbeck, K., Alegría, A., Nicolai, M., Okem, A., Petzold, J., Rama, B. \& Weyer, N. (Eds.). (2019). Summary for Policymakers. En IPCC Special Report on Ocean and Cryosphere in a Changing Climate. Intergovernmental Panel on Climate Change (IPCC). https://www.ipcc.ch/site/assets/uploads/sites/3/2019/11/03_SROCC_SPM_FINAL. pdf 
Queiroz-Sperotto, F. (2018). La formación de paraísos de contaminación: Un estudio de caso de la producción de celulosa en el Cono sur. Revista EURE - Revista de Estudios Urbano Regionales, 44(132), 213-237. https://doi.org/10.4067/s0250-71612018000200213

Red Latinoamericana de Fiscalización y Cumplimiento Ambiental (redlafica). (2019). Plan Estratégico de la Red de Fiscalización y Cumplimiento Ambiental 2019-2021. http:// www.redlafica.org/wp-content/uploads/2019/06/PEI-2019-2021-RedLafica.pdf

Reid, W., Mooney, H., Cropper, A., Capistrano, D., Carpenter, S., Chopra, K., Dasgupta, P., Dietz, T., Kumar, A., Hassan, R., Kasperson, R., Leemans, R., May, R., McMichael, T., Pingali, P., Samper, C., Scholes, R., Watson, R., Zakri, A. H., ... \& Zurek, M. (2005). Evaluación de los Ecosistemas del Milenio. Informe de sintesis. Millenium Ecosystem Assessment. https://www.millenniumassessment.org/documents/document.439.aspx.pdf

Romo Murillo, D. (2007). La competitividad exportadora de los sectores ambientalmente sensibles y la construcción de un patrón exportador sostenible en América Latina y el Caribe. Documento de proyecto. Naciones Unidas / CEPAL. https://repositorio.cepal.org/ bitstream/handle/11362/3582/1/S2007336_es.pdf

Sánchez, L. \& Caballero, K. (2019). La curva de Kuznets ambiental y su relación con el cambio climático en América Latina y el Caribe: un análisis de cointegración con panel, 19802015. Revista de Economía del Rosario, 22(1), 41. https://doi.org/10.12804/revistas. urosario.edu.co/economia/a.7769

Schaper, M. (1999). Impactos ambientales de los cambios en la estructura exportadora de nueve países de América Latina y el Caribe. Serie Medio Ambiente y Desarrollo, 19. Naciones Unidas / CEPAL. https://repositorio.cepal.org/bitstream/handle/11362/5705/2/ S00110941_es.pdf

Servicio de Evaluación Ambiental (sEA), Chile. (2019). Información de Proyectos Ingresados al SEIA. https://www.sea.gob.cl/documentacion/reportes/informacion-de-proyectosingresados-al-seia. Véase también Reportes Estadísticos Mensuales de Proyectos Ingresados en el seia - enero-diciembre 2019. https://sea.gob.cl/documentacion/reportes/reporteestadisticomensual-de-proyectos-en-el-seia-agosto-2016?page $=1$

Stern, D. I. (2004). The rise and fall of the environmental Kuznets curve. World Development, 32(8), 1419-1439. https://doi.org/10.1016/j.worlddev.2004.03.004

Stiglitz, J. E. (2002). El malestar en la globalización. Trad. C. Rodríguez Braun. Taurus.

Stiglitz, J. E. (2018). El malestar en la globalización. La antiglobalización en la era de Trump. Trads. C. Rodríguez Braun \& M. L. Rodríguez Tapia. Taurus.

Superintendencia del Medio Ambiente (sMA), Chile. (2020). Estadísticas y Datos del Sistema Nacional de Información de Fiscalización Ambiental. Sistema Nacional de Información de Fiscalización Ambiental (sNifa). http://snifa.sma.gob.cl/v2/Estadisticas

Tecklin, D., Bauer, C. \& Prieto, M. (2011). Making environmental law for the market: the emergence, character, and implications of Chile's environmental regime. Environmental Politics, 20(6), 879-898. https://doi.org/10.1080/09644016.2011.617172

Temkin Yedwab, B., Ávila Forcada, S. \& Martínez Guerrero, E. (2018). El impacto diferencial de la globalización económica y la democracia sobre las emisiones de $\mathrm{CO}_{2}$ en países ricos y pobres. Revista Internacional de Contaminacion Ambiental, 34(1), 169-183. https://doi.org/10.20937/RICA.2018.34.01.15 
Torres Preciado, V. H. \& Polanco Gaytán, M. (2016). Especialización y contaminación en la industria manufacturera del estado de Colima. Región y Sociedad, 20(41). https://doi. org/10.22198/rys.2008.41.a519

Vega-Quezada, C., Varela-Veliz, G., Martínez-Jiménez, D. \& Soto-González, C. (2019). Perspectivas sobre Crecimiento Económico y Medio Ambiente: Curva Ambiental de Kuznets en la Alianza del Pacífico. Revista Cumbres, 5(2), 23-32. https://doi. org/10.48190/cumbres.v5n2a2

Wehner, L. (2011). El frenesí de Chile por los Tratados de Libre Comercio. Revista de Ciencia Politica, 31(2), 207-226. https://www.redalyc.org/pdf/324/32422457003.pdf

Yale University. (2020). Environmental Performance Index 2020. Global metrics for the environment: Ranking country performance on sustainability issues. Yale Center for Environmental Law \& Policy.

Yu, Y., Feng, K. \& Hubacek, K. (2014). China’s unequal ecological exchange. Ecological Indicators, 47, 156-163. http://dx.doi.org/10.1016/j.ecolind.2014.01.044

Zebryte, I. \& Villegas-Benavente, L. (2016). La teoría del refugio de contaminación: Efectos de la inversión extranjera directa a escala local en Chile. Revista Jurídicas, 13(1), 24-40. https://doi.org/10.17151/jurid.2016.13.1.3

Zilio, M. (2010). La curva de Kuznets ambiental: Evidencia para América Latina y el Caribe. Universidad Nacional del Sur. https://repositoriodigital.uns.edu.ar/ handle/123456789/2156

Zilio, M. (2015). Curva de Kuznets ambiental: la validez de sus fundamentos en países en desarrollo. Cuadernos de Economía, 35(97), 43-54. https://doi.org/10.1016/s02100266(12)70022-5 